\title{
Exploration of Divergent Experimental Teaching for Improving Students' Innovative Practical Ability
}

\author{
ShiSong Zhang ${ }^{1}$, XiaoFang Sun ${ }^{2}$,ZhongShan $\mathrm{Yao}^{3}$
}

\author{
${ }^{1}$ Dalian Naval Academy \\ ${ }^{2}$ Dalian Naval Academy \\ ${ }^{3}$ Dalian Naval Academy \\ ${ }^{1}$ Email: 394403007@qq.com \\ ${ }^{2}$ Email:435523253@qq.com \\ ${ }^{3}$ Email: 327570350@qq.com
}

\begin{abstract}
Divergent thinking refers to a thinking mode that pursues multi-directional, three-dimensional and open conclusions without the constraints of existing methods, laws and concepts. This thinking mode mainly refers to finding different methods to solve relevant problems by combining the thinking methods of expansion, radiation and seeking differences, so as to get different answers, so as to train and improve students' innovative ability in experimental practice. Since the goal of Chinese education and teaching reform is to comprehensively promote the innovative training mode, divergent experimental teaching is a new teaching method to deeply explore the innovative training mode from the ways and means of science education on the premise of meeting the basic practical conditions and laws. The focus of this chapter is to introduce the divergent thinking ability training module into the experimental teaching in colleges and universities. Students, under the guidance of teachers and combined with their own reality, use relevant knowledge and skills to gradually establish original thinking methods and the ability to seek multi schemes and creatively deal with specific problems.
\end{abstract}

Keywords: Divergent thinking, innovative ability, experimental teaching, specific problems.

\section{RESEARCH SIGNIFICANCE}

According to the needs of Chinese innovation driven development strategy, cultivating higher education talents with scientific creative spirit and ability is the key index to evaluate the level of talents, and the experiment and exploration course plays a very important role in cultivating students' scientific research spirit, creativity and practical ability. ${ }^{[1]} \mathrm{At}$ present, the core requirement of the reform of college education is to focus on "changing the traditional teaching methods" and "promoting the innovation of educational ideas", from the previous "focus on the teaching of students' knowledge to the more need to pay attention to the cultivation of development ability and quality education" to the current situation "Organize students to carry out technological innovation experiments and exploration, so as to continuously improve students' innovative spirit and creative learning ability. AS the practical teaching method and management system for the training of research-oriented and innovative talents need to be improved, in recent years, major universities have strengthened their attention to the teaching reform, making the practical teaching reform an important part of the national talent training and improving the practical innovation ability. As a teaching method advocated and used earlier, the divergent teaching method in the past was generally used in the reform and creation of basic theory courses, but there are relatively few attempts to cultivate this thinking method in experimental teaching. Especially at present, in experimental teaching in colleges and universities, because its content is mainly divided into basic confirmatory experiment and comprehensive design experiment, the content requires students not only to have the corresponding subject foundation, but also Therefore, the divergent experimental teaching mode explored under this background is also of great significance to improve the innovative spirit and creativity of college students. 


\section{PROBLEMS FACED BY THE CURRENT MILITARY ACADEMY EXPERIMENTAL COURSE}

First of all, teachers are responsible for all the contents of the experimental course, and many teachers are quite arbitrary in the setting of practical teaching contents, which leads to a serious lack of logic and coherence between the actual contents of some courses and the curriculum system, and individual teachers arbitrarily set their own cognition and mastery of the actual teaching contents of the course, Thus it becomes "teaching for teaching", completely ignoring the relationship between the professional curriculum content and teachers' future specific work and actual teaching, resulting in putting the cart before the horse.

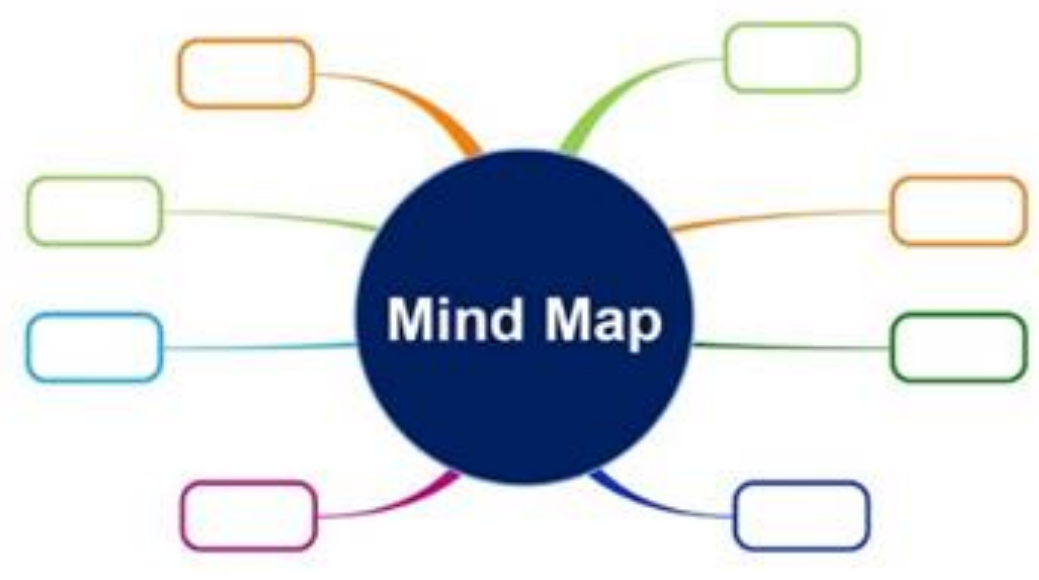

Figure 1 divergent thinking

Secondly, from the perspective of the core content of the experiment, students listen to the introduction of the experimental teacher more and do their own experiments less in the process of actual operation; talk more and do their own experiments less; summarize more past experience (case analysis and Exploration), but have less in-depth experience.

Thirdly, it pursues too much consistency with the experimental results described in books. ${ }^{[2]}$ At the same time, it also lacks interest in the real operation process due to insufficient understanding of the principle and application scope of experimental equipment, and students rarely think divergently.

\section{HOW TO USE DIVERGENT TEACHING METHODS TO IMPROVE THE TEACHING QUALITY OF EXPERIMENTAL COURSES}

The so-called divergent thinking refers to a thinking mode in an expanded state when the human brain thinks about various problems. Its main characteristics are that the thinking horizon is broad and the thinking perspective presents a multi-dimensional diffusion trend. In the field of educational psychology, taking divergent thinking as an important mark of creativity is the most important feature of innovative thinking. [3] Through the use of divergent thinking to solve problems, teachers can extend their ideas from different directions, and finally form various possible answers rather than the only reasonable answers, so it is easier to form innovative new ideas. The experimental teaching of diffusive thinking is a course entered on knowledge points. In this process, teachers and students need to solve problems through joint research, At the same time, it requires that experimental teachers must have rich educational experience and high research level. The experimental class not only lays the foundation of students' professional knowledge, but also improves students' self-active practical experience and cognition, so as to promote students not only to "how to learn", but also to learn "How to think", but also "how to do", and finally cultivate the comprehensive ability to find, analyse and solve problems.

(1) While striving to cultivate and improve teachers' quality, they should increase their experience in grassroots substitute work, so that they can have more opportunities to contact grass-roots forces and understand the needs of grass-roots forces, so that their contents can be more consistent with students' future work in experimental teaching and scheme design.

(2) Cultivate students' interest in divergent thinking and make them diligent in thinking and doing. People all understand that interest is the main source of creativity, so teachers can often use classroom settings and adjustments to mobilize students' interest in exploration and cultivate their interest in subjects, so as to create a certain space for students' ideas. Hegel, the great German thinker, said that "thinking requires rich imagination". Therefore, in teaching, we should also pay attention to improving students' innovative consciousness, cultivating their interest in "fantastic ideas" and creating space and opportunities for their "unrestrained" imagination. 
(3) Pay attention to the divergent guidance of the experimental classroom. Before teaching the experimental classroom, teachers should first determine the key problems to be solved in the classroom, the problems that can be raised, and what methods can be used to solve them, and then arrange the teaching contents to the students in advance. ${ }^{[4]}$ During the class discussion, students need to put forward at least three different experimental methods, and then discuss them in groups, classroom discussion and analysis are carried out according to the conclusions of the experiment, so that students can gradually establish a comprehensive and overall cognitive ability, improve students' sense of achievement in their past work, and then improve their understanding of the knowledge system. Through this specific experimental process, students are required to integrate personal creative thinking, similar to the process of scientific research, so as to train and inspire students' creativity.

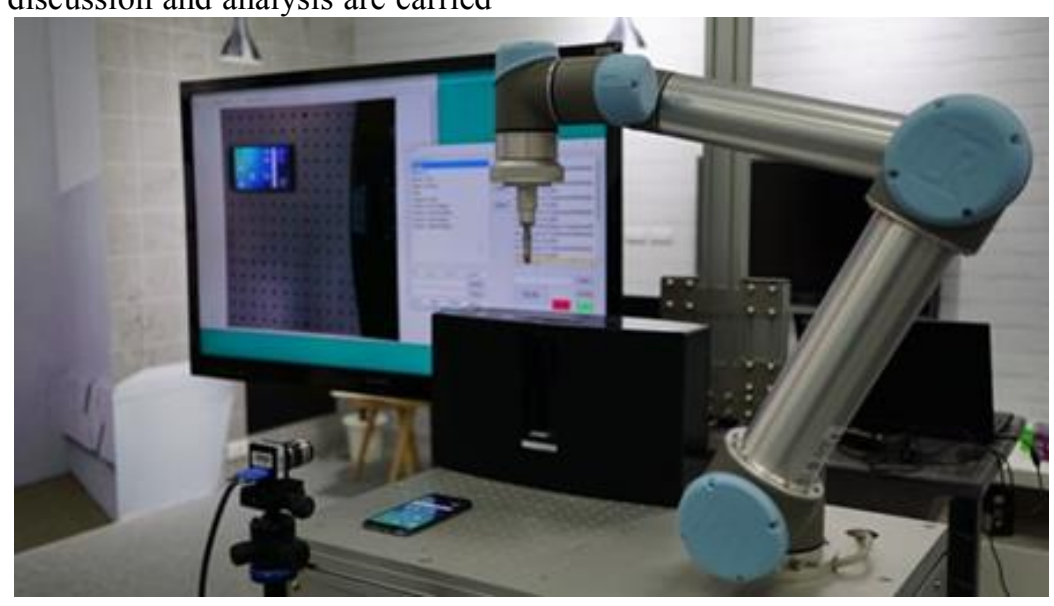

Figure 2 divergent experimental

(4) Actively create a relaxed educational environment, promote students' individualized development and the cultivation of divergent thinking habits. By forming an open teaching atmosphere and promoting students' active learning of relevant documents before class, students can question the theories and views explained by teachers, as well as the relevant contents in textbooks and papers at any time in class. ${ }^{[5]}$ In the process of questioning, students can promote "Students learn creatively" and "teachers teach creatively" In addition, efforts should be made to improve the openness of each teaching laboratory and the guarantee of corresponding software and hardware conditions, including setting up appropriate open innovation laboratories and shared instrument laboratories to improve students' autonomous learning time, allow students to try themselves. At the same time, they can also try to carry out network courses to realize network management of relevant experimental theories, basic skills and methods, relevant electronic resources and materials used in practice, teaching content, etc. so that students can realize free preview, simulation training and practical testing, so as to form a comprehensive and loose educational environment.

(5) Pay attention to the divergent evaluation of the conclusion of the experimental course

At present, an important factor causing the low effect of teaching quality is the formalism in the evaluation of actual teaching quality. ${ }^{[6]}$ Although many researchers have given some views and opinions on the experiment and teaching in colleges and universities, the real implementation is still not in place. The key lies in the excessive pursuit of the unity of the experimental results and the lack of understanding of the experimental process Evaluation of dimensions.

The divergent experimental teaching requires teachers to provide students with more evaluation criteria as much as possible in the course evaluation stage, pay attention to guiding students to find potential orthogonal protective factors on the basis of comprehensively mastering and excavating relevant knowledge in the course, do not evaluate students with "only accurate answer", and help students establish "not only books, not superstitious teachers and not trusting others" Guide students to think about innovation issues and explore innovative ways of thinking along new perspectives and new ways.

\section{CONCLUSIONS}

This paper mainly discusses the problems encountered in the process of teaching reform in Colleges and universities, and introduces divergent experimental teaching methods to solve these problems. The purpose is to continuously improve the teaching quality of colleges and universities, improve students' practical ability, lay a more solid foundation for their future work and contribute to the development of education. 


\section{REFERENCES}

[1] Callan Gregory L.; DaVia Rubenstein Lisa; Ridgley Lisa M.; Speirs Neumeister Kristie; Hernandez Finch Maria; Longhurst David, Measuring and Predicting Divergent Thinking With a Self-Report Questionnaire, Teacher Rating Scale, and SelfRegulated Learning Microanalysis, USA, $10.1177 / 07342829211005288$.

[2] Youyi Wang, On the cultivation of divergent thinking, Focus on education reform, Hubei, Heidelberg, 2013-10.

[3] Thakral Preston P; Yang Amanda C; Addis Donna Rose; Schacter Daniel L, Divergent thinking and constructing future events: dissociating old from new ideas. USA, 10.1080/09658211.2021.1940205.

[4] Lee Jin Woo; Daly Shanna R.; Huang Saad Aileen; Rodriguez Gabriella; DeVries Quinton; Seifert Colleen M., A solution in search of problems: a cognitive tool for solution mapping to promote divergent thinking, USA, 10.1080/09544828.2021.1887462.

[5] Beaty Roger E.; Zeitlen Daniel C.; Baker Brendan S.; Kenett Yoed N. Forward Flow and Creative Thought: Assessing Associative Cognition and its Role in Divergent Thinking, USA, 10.1016/J.TSC.2021.100859.

[6] Judd Adrian; Lonsdale Jemma-Anne, Applying systems thinking: The Ecosystem Approach and Natural Capital Approach - Convergent or divergent concepts in marine management? Centre for Environment, Fisheries and Aquaculture Science, Pakefield Road, Lowestoft, Suffolk NR33 0HT, UK, 10.1016/J.MARPOL.2021.104517. 